\title{
Effect of Extraction Solvent on the Recovery of Bioactive Substances of Dry Salted Olives
}

\author{
Ouahiba, Soufi., Salima, Zemouri., Hayette, Louaileche* \\ Laboratoire de Biochimie Appliquée, Faculté des Sciences de la Nature et de la Vie, Université de Bejaia, Bejaia, Algérie
}

*Corresponding author: Hayette, Louaileche. Laboratoire de Biochimie Appliquée, Faculté des Sciences de la Nature et de la Vie, Université de Bejaia, 06000 Bejaia, Algérie, Tel: +213-34 214762 ; E-mail: haylouaileche@yahoo.fr

\begin{abstract}
Extraction of phenolic compounds from olive processed with dry salt was studied. Extraction experiments were carried out by investigating the effect of solvent (acetone, ethanol and methanol) and it concentration (50-90\%) on the recovery of bioactive substances (phenolic compounds and flavonoids) and the antioxidant activity (reducing power and radical scavenging activity against stable DPPH radical) of the extracts. The results showed that the nature and the concentration of solvent affect significantly $(\mathrm{p}<0.05)$ the phenolic content and antioxidant activities of olive extracts. The highest content of total phenolics $(2.75 \mathrm{~g} / 100 \mathrm{~g})$ was recorded with $50 \%$ acetone, while the highest flavonoid contents were obtained in both $50 \%$ and $70 \%$ ethanol $(1.07$ $\mathrm{g} / 100 \mathrm{~g}$ ). Furthermore, the extracts of $50 \%$ acetone exhibit the best antioxidant activity. However, the strongest antiradical activity was achieved with $50 \%$ ethanol $(776$ $\mathrm{mg} / 100 \mathrm{~g}$ ). On the other hand, the antioxidant activity was found to be positively correlated with bioactive substances.
\end{abstract}

Keywords: Dry salted olives; Bioactive substances; Extraction; Antioxidant
Received Date: August 24, 2016

Accepted Date: September 17, 2016

Published Date: September 22, 2016

Citation: Soufi, O., et al. Effect of Extraction Solvent on the Recovery of Bioactive Substances of Dry Salted Olives. (2016) J Anal Bioanal Sep Tech 1(1): 1216.

DOI: $10.15436 / 2476-1869.16 .1060$

\section{Introduction}

The olive tree (Olea europaea L.) is widely cultivated in many regions of the world where climatic conditions are as favourable as those prevailing in the Mediterranean countries. During the last decade, the evolution of the Algerian market concerning table olives was characterized by a production that has evolved in a fluctuating trend of olive crop to another. Algeria's olive crop area was around 188,923 ha by 2011 . The total table olive production was estimated to 192,785 tons in $2011^{[1]}$.

In recent years, particular attention has been focused on the olive phenolics which contribute to the total antioxidant potential of the diet and thus may lower the risk of cancer and chronic diseases ${ }^{[2,3]}$. However, these are a diverse class of molecules with different structures and they are often combined with other substances (proteins, polysaccharides, terpenes, chlorophyll $)^{[4]}$. On the other hand, many factors can affect the extraction efficiency of phenolic compounds, including, solvent nature and concentration, particle size of plant materials, extraction time and temperature, and solvent to solid ratio ${ }^{[5,6]}$.
Hence, the purpose of this study which is devoted to investigate the effect of solvent nature (acetone, ethanol and methanol) and concentration (50 - 90\%) on the extraction of antioxidant substances (total phenolic compounds and flavonoids) of dry salted olives. The antioxidant activity of the extracts was also estimated using three methods: the ferric reducing power, molybdenum reducing activity and antiradical activity.

\section{Materials and Methods}

\section{Olive samples}

Three samples of black olives (Azeradj cultivar) were harvested at the fully ripe stage, were hand-picked from different parts of olive trees in Bejaia location (north of Algeria).

\section{Processing of olive samples}

The collected olives (at least $2 \mathrm{Kg}$ ) were treated with alternating layers of dry salt $(0.8 \mathrm{Kg})$, into baskets, and kept at 
room temperature for 50 days ${ }^{[7]}$. The salting caused dehydration and the olives appear shriveled. The obtained olive pulps were freeze-dried (Christ, Alpha 1-4 LDplus, Osterode am Harz, Germany), then ground in electric blender (IKA model A 11 B, Staufen, Germany) and stored at $-18^{\circ} \mathrm{C}$ until analysis.

\section{Extract preparation}

Freeze dried olive pulp (100 mg) was homogenized in $10 \mathrm{~mL}$ of extraction solvent: three different solvents [acetone (A), ethanol (E) and methanol (M)] were used at different concentrations $(50 \%, 70 \%$ and $90 \%)$. After stirring for $30 \mathrm{~min}$ at room temperature, the mixture was centrifuged (nüve NF 200, Ankara, Turkey) at 2800x g for $20 \mathrm{~min}$, at room temperature. This procedure is repeated twice. The filtered extracts were combined, washed with hexane $(5 \times 10 \mathrm{~mL})$, and then kept in refrigerator until analysis ${ }^{[8]}$.

\section{Phenolic compounds analysis}

1. Total phenolic compounds: The total phenolic content of extracts was determined according to Kahkönen et al ${ }^{[9]}$. Aliquots $(200 \mu \mathrm{L})$ of extract were mixed with $1 \mathrm{~mL}$ of Folin-Ciocalteu reagent and $800 \mu \mathrm{L}$ of sodium carbonate $(7.5 \%)$. After incubation for $30 \mathrm{~min}$, the absorbance was measured at $725 \mathrm{~nm}$ (Uvi-mini 1240 spectrophotometer, Shimadzu, Suzhou, China). The total phenolic content was expressed as mg of gallic acid equivalents (GAE)/100 g of dry weight, using a standard calibration curve.

2. Total flavonoids: Total flavonoid contents were measured according to Kim et $\mathrm{al}^{[10]}$. An aliquot of sample $(200 \mu \mathrm{L})$ was mixed with distillated water $(800 \mu \mathrm{L})$. A volume of $60 \mu \mathrm{L}$ of $5 \% \mathrm{NaNO}_{2}$ was added to the flask. After $5 \mathrm{~min}, 60 \mu \mathrm{L}$ of $10 \%$ $\mathrm{AlCl}_{3}$ were added. At $6 \mathrm{~min}, 40 \mu \mathrm{L}$ of sodium hydroxide $(1 \mathrm{M})$ were added to the mixture. Immediately, the contents of the reaction flask were diluted with $480 \mu \mathrm{L}$ of water and thoroughly mixed. Absorbance of the mixture was determined at $510 \mathrm{~nm}$. Catechin was used as standard and the results were calculated as milligrams of catechin equivalents (CE) per $100 \mathrm{~g}$ of dry weight, using a standard calibration curve.

\section{Antioxidant Activity}

1. Reducing power: The reducing power was estimated using the procedure described by Gülçin et al ${ }^{[11]}$. A volume of olive extract $(250 \mu \mathrm{L})$ was mixed with $250 \mu \mathrm{L}$ of phosphate buffer (0.2 M, pH 6.6) and $250 \mu \mathrm{L}$ of potassium ferricyanide (1\%). The mixture was incubated at $50^{\circ} \mathrm{C}$ for $20 \mathrm{~min}$. Aliquot $(250 \mu \mathrm{L})$ of trichloroacetic acid $(10 \%)$ and $200 \mu \mathrm{L}$ of ferric chloride $(0.1 \%)$ were added to the mixture. The absorbance was measured at 700 $\mathrm{nm}$ and the results were calculated as $\mathrm{mg}$ of ascorbic acid equivalents (AAE)/100 g of dry weight.

2. Phosphomolybdenum reduction assay: Total antioxidant activity of olive extracts has been assessed with the phosphomolybdenum reduction assay according to Prieto et $\mathrm{al}^{[12]}$. Briefly, $0.2 \mathrm{~mL}$ of olive extract were mixed with $2 \mathrm{~mL}$ of reagent $(0.6 \mathrm{M}$ sulfuric acid, $28 \mathrm{mM}$ sodium phosphate and $4 \mathrm{mM}$ ammonium molybdate). The mixture was incubated at $95^{\circ} \mathrm{C}$ for $90 \mathrm{~min}$ and the absorbance of the green phosphomolybdenum complex was measured at $695 \mathrm{~nm}$. Total antioxidant activity is expressed as mg GAE/100 g dry weight.
3. DPPH free radical scavenging activity: The antiradical activity of olive extracts was evaluated according to Lesage-Meessen et al ${ }^{[13]}$. An aliquot of olive extract $(100 \mu \mathrm{L})$ was mixed with $900 \mu \mathrm{L}$ of $60 \mu \mathrm{M}$ solution DPPH (1, 1-diphenyl-2-picrylhydrazyl radical). The reaction mixture was vortex-mixed and let in the dark for $30 \mathrm{~min}$. The absorbance was measured at $517 \mathrm{~nm}$ and the antiradical activity was expressed as mg of ascorbic acid equivalents (AAE)/100 g of dry weight.

\section{Statistical Analysis}

Results were expressed as mean \pm standard deviation (SD).Statistical analysis of the data was carried out with STATISTICA 5.5 Fr. Analysis of variance (ANOVA) was performed to estimate the statistically significant differences between olive samples for each parameter. $\mathrm{P}$ values $<0.05$ were regarded as significant.

\section{Results and Discussion}

\section{Phenolic compounds}

1. Total phenolic compounds: The results showed significant differences in the total phenolic contents between the tested solvent $(\mathrm{P}<0.05)$ (figure 1$)$. The nature of solvent and its concentration affect significantly the phenolic contents. 50\% acetone was found to be the most efficient solvent for extracting these compounds with a content of $2.75 \mathrm{~g} \mathrm{GAE} / 100 \mathrm{~g}$, whereas $90 \%$ ethanol gave the lowest recovery of total phenolics $(293 \mathrm{mg} / 100$ $\mathrm{g})$. These results are in concordance with those of Al-Farsi and Lee $^{[14]}$ who demonstrated that $50 \%$ acetone was the best solvent for extraction of phenolic compounds from date fruit. The extraction efficiency of phenolic compounds from olive decreased in the order: $50 \%$ acetone $>50 \%$ methanol $>50 \%$ ethanol $>$ $70 \%$ methanol $>70 \%$ acetone $>70 \%$ ethanol $=90 \%$ methanol $>$ $90 \%$ acetone $>90 \%$ ethanol. We noted that the phenolic content decreased with the increase in the proportion of solvent; the ratio of $50 \%$ seems to be the best for the extraction of these compounds. Lapornik et a ${ }^{[15]}$, and Liyana-Pathirana and Shahidi ${ }^{[16]}$ demonstrated that the use of water in combination with organic solvents contributes to the creation of a moderately polar medium which extracts the total phenolic compounds. On the other hand, the solubility of phenolics is affected by the polarity of solvent used for extraction ${ }^{[17]}$.

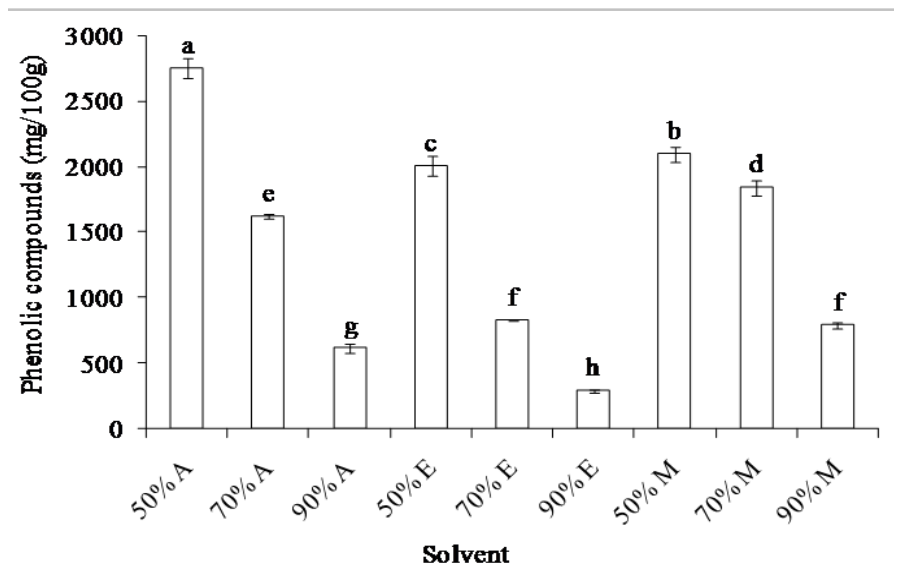

Figure 1: Effect of solvent on phenolic content determined by FolinCiocalteu method

Acetone (A), ethanol (E) and methanol (M) 
According to Zhao and Hall ${ }^{[18]}, 40$ - $60 \%$ solvents allow obtaining extracts with high phenolic contents. Acetone should be selected among other solvents for the extraction of phenolic compounds since it reduces enzyme activity and oxidation, particularly after thawing or grinding that may damage the fruit ${ }^{[19]}$.

2. Total flavonoids: The amount of flavonoids in the extracts obtained by using various solvents of different polarities showed significant differences $(p<0.05)$ (figure 2 ). Both $50 \%$ ethanol and $70 \%$ ethanol had a similar extraction efficiency $(1.07$ $\mathrm{g} \mathrm{GAE} / 100 \mathrm{~g})$, whereas, the lowest flavonoid content $(151 \mathrm{mg}$ GAE/100 g) was obtained by using 70\% methanol. The results indicated that the efficiency of the solvents for flavonoid extraction decreased in the order: $50 \%$ ethanol $=70 \%$ ethanol $>$ $50 \%$ acetone $>70 \%$ acetone $>90 \%$ ethanol $>90 \%$ acetone $>$ $90 \%$ methanol $>50 \%$ methanol $>70 \%$ methanol. It is noted that among the solvents used, $50-70 \%$ ethanol is more appropriate for the extraction of these substances.

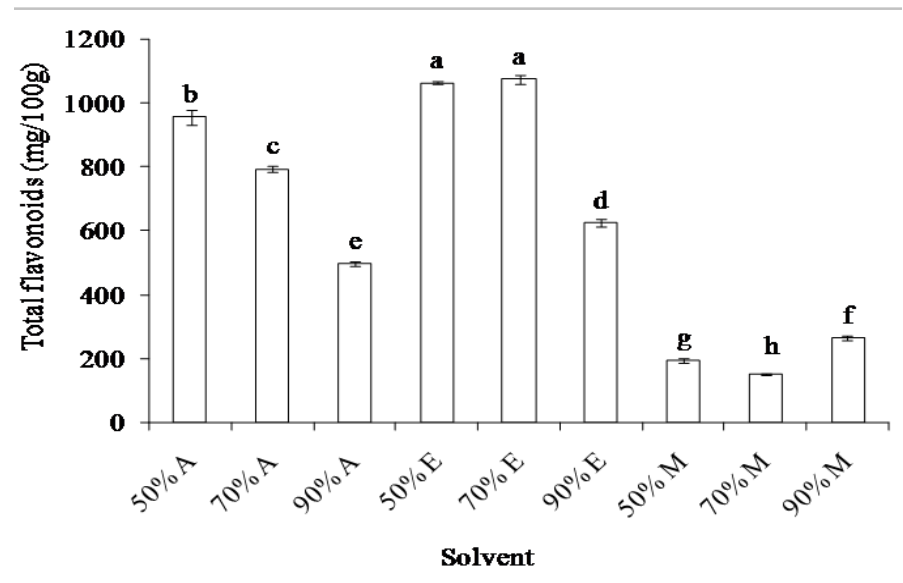

Figure 2: Effect of solvent on flavonoid extraction Acetone (A), ethanol (E) and methanol (M)

\section{Antioxidant activity}

1. Ferric reducing power: The presence of reducing agents in the extracts induced the reduction of $\mathrm{Fe}^{3+}$ to $\mathrm{Fe}^{2+}$. The reducing ability of a compound can serve as a significant indicator of its antioxidant potential. The ferric reducing power of the investigated extracts showed significant differences $(p<0.05)$ (figure 3).

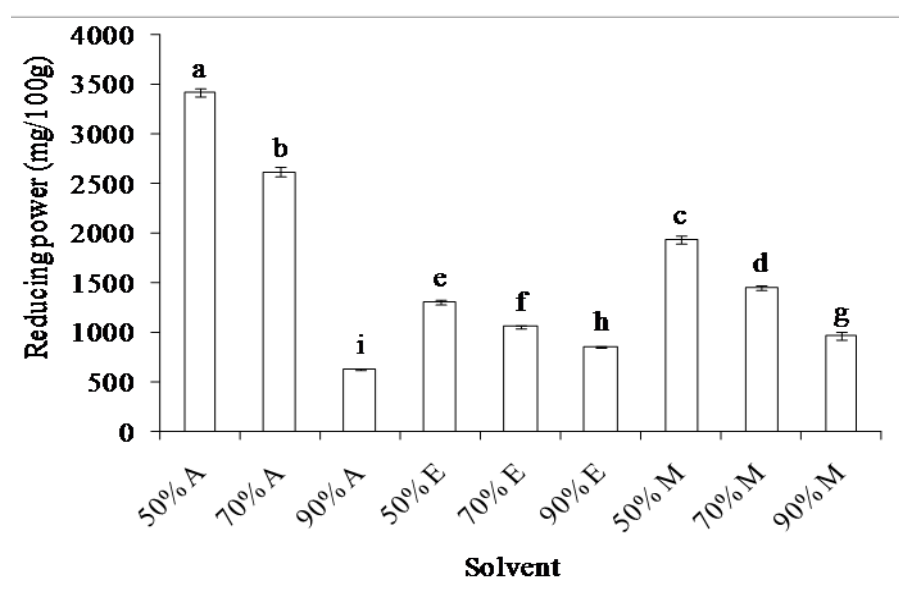

Figure 3: Effect of extraction solvent on ferric reducing power Acetone (A), ethanol (E) and methanol (M)
The 50\% acetone extracts exhibit the highest ferric reducing power (3.42 g AAE/100 g) while 90\% acetone extracts had the lowest one $(634 \mathrm{mg}$ AAE/ $100 \mathrm{~g}) .70 \%$ acetone extracts also showed a considerable reducing capacity. These results are in agreement with those obtained by Liu and $\mathrm{Yao}^{[20]}$, who found that the reducing power of $70 \%$ acetone extract of barley seeds is very high. On the other hand, Sousa et al ${ }^{[21]}$. demonstrated that the reducing power of methanolic extracts of table olives is higher than that of aqueous ones. The differences observed between the extracts could be explained by the different contents of total phenolics of the extracts, due to the major role of these compounds in the ferric reducing capacity. Also, the solubility of phenolic compounds in the different solvents may be the cause of these variations.

2. Molybdenum reduction assay: Figure 4 showed significant differences in antioxidant activity between the studied olive extracts $(\mathrm{P}<0.05)$ : nature and concentration of solvent affect significantly the antioxidant activity. The highest activity is recorded for $50 \%$ acetone extracts $(5.73 \mathrm{~g} / 100 \mathrm{~g})$, while the lowest one is observed with $90 \%$ ethanol extract $(817 \mathrm{mg} / 100 \mathrm{~g})$. The effectiveness of the solvents used for the estimation of the molybdenum reducing activity of olive extracts decreased in the following order: $50 \%$ acetone $>50 \%$ methanol $>70 \%$ acetone $>$ $50 \%$ ethanol $=70 \%$ methanol $>70 \%$ ethanol $>90 \%$ acetone $>$ $90 \%$ methanol $>90 \%$ ethanol. It appears that $50 \%$ acetone extracts which contain the highest levels of phenolic compounds, exhibit the best reducing activity; this reflects the role of such substances in the reducing activity. However, the difference in the antioxidant capacity of various extracts could be due to the different polarities of antioxidant compounds in each extract, and/or their electron-donating activity.

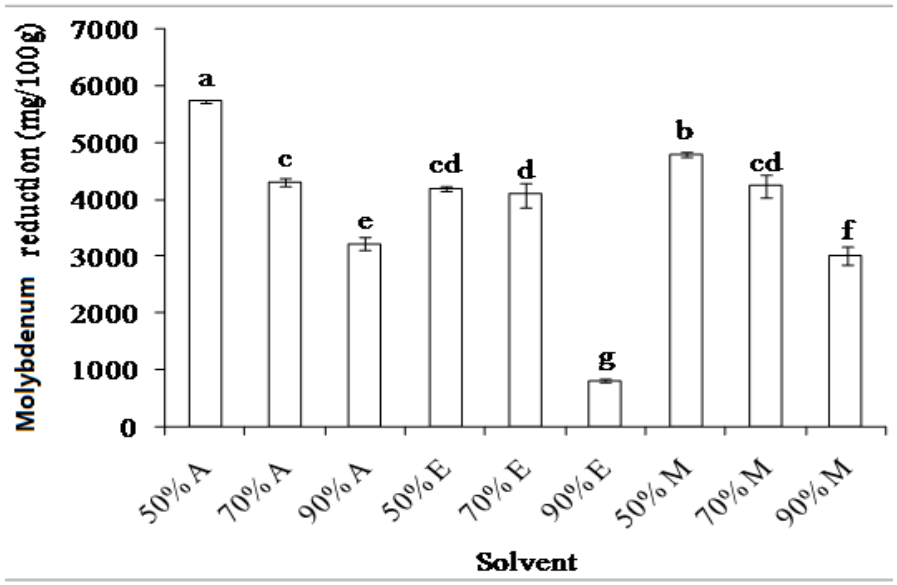

Figure 4: Effect of extraction solvent on total antioxidant activity Acetone (A), ethanol (E) and methanol (M)

3. DPPH free radical scavenging activity: The radical scavenging activity obtained was presented on figure 5 . The statistical analysis showed that the olive extracts have significant different capacities $(p<0.05)$ to yield hydrogen to act as antioxidants, depending on the solvent used. $50 \%$ ethanol extracts exhibit the highest radical scavenging activity (776 mg AAE/100 g) unlike $90 \%$ methanol extracts which present the lowest one $(16 \mathrm{mg} \mathrm{AAE} / 100 \mathrm{~g})$. The moderately polar ethanol extracts are very effective for trapping DPPH radical due to their high content of phenolic acids and flavonoid glycosides ${ }^{[22]}$. The efficiency of solvents used for the determination of antiradical activity 
of olives extracts decreased in the following order: $50 \%$ ethanol $>50 \%$ acetone $>70 \%$ ethanol $>70 \%$ acetone $>50 \%$ methanol $>70 \%$ methanol $>90 \%$ acetone $>90 \%$ ethanol $>90 \%$ methanol. According to Türkmen et al ${ }^{[23]}$, extracts prepared with $50 \%$ solvents showed significantly high DPPH scavenging capacity, which is in agreement with our results. The differences found between tested extracts may be due to the type and polarity of solvent which affect the transfer of hydrogen ${ }^{[24]}$. Besides, the use of solvents with different polarities allows the extraction of a selected group of antioxidants, affecting the antioxidant capacity evaluation $^{[25]}$.

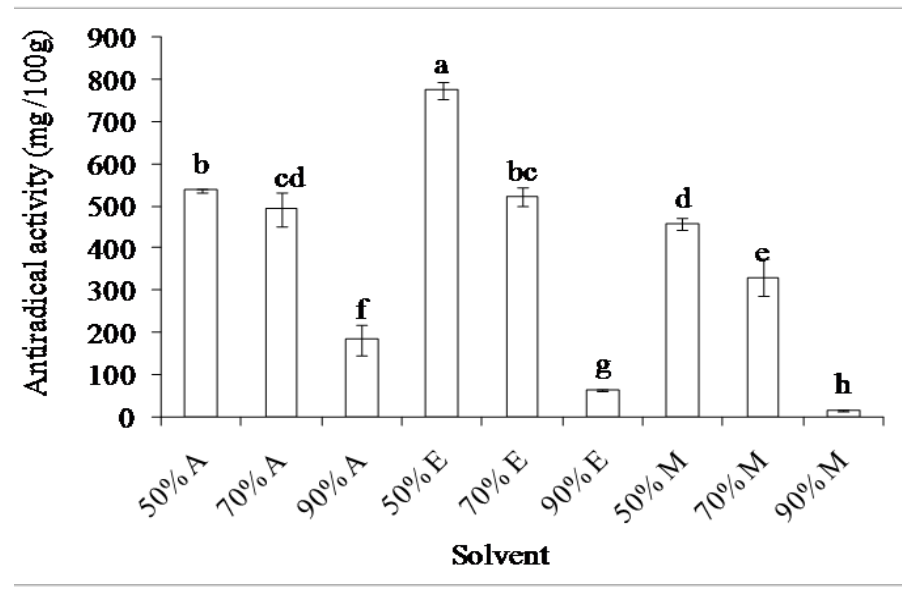

Figure 5: Effect of extraction solvent on antiradical activity Acetone (A), ethanol (E) and methanol (M)

\section{Correlation between antioxidant activities and phytochemi- cal compounds}

The results indicated that all tested olive extracts showed a linear relationship with a positive correlation coefficient $(\mathrm{p}<0.05)$ between total phenolics and antioxidant activity which was given by the ferric reducing power $(\mathrm{R}=0.81)$, molybdenum reduction potential $(\mathrm{R}=0.86)$ and antiradical activity $(\mathrm{R}=0.70)$. This relationship suggested that the phenolic compounds of dry salted olive extracts might be the major contributors to the tested antioxidant activities.

A linear relationship is found between flavonoids and antioxidant activity evaluated by molybdenum reduction activity with a positive correlation coefficient $(\mathrm{p}<0.05)$ of 0.62 . However, a low correlation was noted between these substances and the antioxidant activity evaluated by reducing power and antiradical activity. This means that the antioxidant activity is not only related to the phenolic compounds concentration, but it depend also on it structure.

\section{Conclusion}

This study demonstrated the effect of the extraction solvent on the phenolic content and antioxidant activity of dry salted olives. The type and concentration of solvent affect significantly the levels of phenolic compounds and antioxidant activity of olive extracts. $50 \%$ acetone is the most efficient solvent for extraction of the total phenolics. Concerning the flavonoids, both $50 \%$ and $70 \%$ ethanol are the best solvents with similar extraction efficiency.

The highest reducing power is recorded for $50 \%$ acetone extracts. Regarding anti-radical activity, the highest values are recorded in the $50 \%$ ethanol extracts. The $50 \%$ acetone ex- tracts also exhibit considerable antiradical activity.

The results indicated that selective extraction from olives, with appropriate solvents, is important for obtaining extracts having high antioxidant activity. Therefore, it is recommended to avoid the use of solvents with high water content for the extraction of phenolic compounds. Other parameters rather than the extraction solvent can be used as opportunities to optimize the best extraction in view of its use on an industrial scale.

Acknowledgements: Thanks are due to Ifri-Olive, Mr Ait Kheddache S. and all persons who have harvested the olive samples of this study, and the Algerian Ministry of Higher Education and Scientific Research who funded this work.

\section{Reference}

1. ITAFV. Technical Institute of Fruit Trees and Vines . 2011 statistics table olives . Study Department Directorate General (Algiers).

2. Bianchi, G., Lipids and phenols in table olives. (2003) Eur J Lipid Sci Tech 105(5): 229-242.

3. Soni, M.G., Burdock, G.A., Christian, M.S., et al. Safety assessment of aqueous olive pulp extract as an antioxidant or antimicrobial agent in foods. (2006) Food Chem Toxicol 44(7): 903-915.

4. Monpon, B., Lemaire, B., Mengal, P., et al. Extraction des polyphénols: du laboratoire à la production industrielle. In «Polyphénols 96». Edition: INRA. Bordeaux, France. (1996)

5. Chirinos, R., Rogez, H., Campos, D., et al. Optimization of extraction conditions of antioxidant phenolic compounds from mashua (Tropaeolum tuberosum Ruíz\&Pavón) tubers. (2007) Sep Purif Technol 55(2): 217-225.

6. Stankovic, M.S., Topuzokiv, M.D., In vitro antioxidant activity of extracts from leaves and fruits of common dogwood (Cornus sanguinea L.). (2012) Acta Bot Gall 159(1): 79-83.

7. Panagou, E.Z., Greek dry-salted olives: Monitoring the dry-salting process and subsequent physico-chemical and microbiological profile during storage under different packing conditions at 4 and $20^{\circ} \mathrm{C}$. (2006) Lebensm Wiss Technol 39(4): 322-329.

8. Mc Donald, S., Prenzler, P.D., Antolovich, et al. Phenolic content and antioxidant activity of olive extracts. (2001) Food Chem 73(1): 73-84.

9. Kahkönen, M.P., Hopia, A.I., Vuorela, H.J., et al. Antioxidant activity of plant extracts containing phenolic compounds. (1999) J Agric Food Chem 47(10): 3954-3962.

10. Kim, D.O., Chun, O.K., Kim, Y.J., et al. Quantification of polyphenolics and their antioxidant capacity in fresh plums. (2003) J Agric Food Chem 51(22): 6509-6515.

11. Gülçin, İ., Oktay, M., Küfrevioğlu, İ., et al. Determination of antioxidant activity of lichens Cetraria islandica (L) Ach. (2002) J Ethnopharmacol 79(3): 325-329.

12. Prieto, P., Pineda, M., Aguilar, M. Spectrophotometric quantitation of antioxidant capacity through the formation of a phosphomolybdenum complex: specific application to the determination of vitamin E. (1999) Anal Biochem 269(2): 337-341.

13. Lesage-Meessen, L., Navarro, D., Maunier, S., et al. Simple phenolic content in olive oil residues as a function of extraction systems. (2001) Food Chem 75(4): 501-507.

14. Al-Farsi, M.A., Lee, C.Y. Optimization of phenolics and dietary fibre extraction from date seeds. (2008) Food Chem 108(3): 977-985.

15. Lapornik, B., Prošek, M., Wondra, A.G. Comparison of extracts prepared from plant by-products using different solvents and extraction time. (2005) J Food Eng 71(2): 214-222.

16. Liyana-Pathirana, C., Shahidi, F. Optimization of extraction of phenolic compounds from wheat using response surface methodology. (2005) Food Chem 93(1): 47-56. 
17. Naczk, M., Shahidi, F. Extraction and analysis of phenolics in food. (2004) J Chromatogr A 1054(1-2): 95-111.

18. Zhao, B., Hall, C.A. Composition and antioxidant activity of raisin extracts obtained from various solvents. (2008) Food Chem 108(2): 511-518.

19. Moyer, R.A., Hummer, K.E., Finn, C.E., et al. Anthocyanins, phenolics, and antioxidant capacity in diverse small fruits: Vaccinium, $R u$ bus, and Ribes. (2002) J Agric Food Chem 50(3): 519-525.

20. Liu, Q., Yao, H. Antioxidant activities of barley seeds extracts. (2007) Food Chem 102(3): 732-737.

21. Sousa, A., Ferreira, I.C.F.R., Barros, L., et al. Effect of solvent and extraction temperatures on the antioxidant potential of traditional stoned table olives "alcaparras". (2008) LWT - Food Sci Technol 41(4): 739-745.

22. Kouri, G., Tsimogiannis, D., Bardouki, H., et al. Extraction and analysis of antioxidant components from Origanum dictamnus. (2007) Innovative Food Sci Emerging Technol 8(2): 155-162.

23. Turkmen, N., Sari, F., Velioglu, Y.S. Effects of extraction solvents on concentration and antioxidant activity of black and black mate tea polyphenols determined by ferrous tartrate and Folin-Ciocalteu methods. (2006) Food Chem 99(4): 835-841.

24. Jayaprakasha, G.K., Patil, B.S. In vitro evaluation of the antioxidant activities in fruit extracts from citron and blood orange. (2007) Food Chem 101(1): 410-418.

25. Zhou, K., Yu, L. Effects of extraction solvent on wheat bran antioxidant activity estimation. (2004) LWT - Food Sci Technol 37(7): 717-721. 